\title{
The Dysregulated Expression of KCNQ10T1 and Its Interaction with Downstream Factors miR-145/CCNE2 in Breast Cancer Cells
}

\author{
Weiliang Feng ${ }^{\mathrm{a}}$ Chen Wang ${ }^{\mathrm{a}}$ Chenlu Liang ${ }^{\mathrm{a}}$ Hongjian Yang ${ }^{\mathrm{a}}$ Daobao Chen ${ }^{\mathrm{a}}$ \\ Xingfei Yu ${ }^{a}$ Wenyan Zhao $^{b}$ Donghua Geng ${ }^{b}$ Shuqiang Li ${ }^{b}$ Zhaofu Chen ${ }^{c}$ \\ Ming Sunc
}

aDepartment of Breast Surgery, Zhejiang Cancer Hospital, Hangzhou, bDepartment of General Surgery, Shengjing Hospital Affiliated China Medical University, Shenyang, 'Department of Urology, Shengjing Hospital Affiliated China Medical University, Shenyang, China

\section{Key Words}

LnCRNA • KCNQ1OT1 • Breast cancer • miR-145 • CCNE2

\begin{abstract}
Background/Aims: Next-generation sequencing (NGS) has revealed abundant long noncoding RNAs (IncRNAs) that have been characterized as critical components of cancer biology in humans. The present study aims to investigate the role of the IncRNA KCNQ1OT1 in breast cancer (BRCA) as well as the underlying molecular mechanisms and functions of KCNQ1OT1 involved in the progression of BRCA. Methods: The Cancer Genome Atlas (TCGA) and StarBase v2.0 were used to obtain the required gene data. Dual luciferase reporter gene assays were conducted to verify the relevant intermolecular target relationships. QRT-PCR and Western blot were performed to measure the expression levels of different molecules. Cell proliferation was detected by using the MTT and colony formation assays, while cell migration and invasion were examined by transwell assay. Variations in cell apoptosis and cell cycle were determined through flow cytometry. A tumor xenograft model was applied to assess tumor growth in vivo. Results: KCNQ1OT1 was found to be remarkably highly expressed in BRCA tissues and cells. KCNQ1OT1 modulated CCNE2 through sponging miR-145 in BRCA. KCNQ1OT1 promoted tumor growth in vivo by regulating miR-145/CCNE2. Conclusion: The KCNQ1OT1/miR-145/CCNE2 axis plays a critical regulatory role in BRCA, potentially giving rise to BRCA tumorigenesis and progression. These findings provide valuable evidence for improving the diagnosis and treatment of BRCA in the future.
\end{abstract}




\section{Cellular Physiology Cell Physiol Biochem 2018;49:432-446 \begin{tabular}{ll|l} 
DOI: 10.1159/000492978 & O 2018 The Author(s). Published by S. Karger AG, Basel \\
www.karger.com/cpb
\end{tabular} \\ Feng et al.: LnCRNA KCNQ1OT1 Promotes Breast Cancer}

\section{Introduction}

Breast cancer (BRCA) is one of the leading causes of cancer-related mortality worldwide and is the most common malignancy in the female population [1]. Approximately $90 \%$ of BRCA-related mortality is attributed to the formation of metastatic lesions [2,3]. Despite the application of systematic adjuvant therapies, such as radiotherapy, chemotherapy, hormone treatment and biological therapy, the overall survival for late-stage patients remains dismal [4]. The mortality rate of BRCA has increased rapidly in recent years, with 252, 710 new cases and 40, 610 deaths estimated in the United States during 2017 [5].

Emerging research has shown that numerous molecular triggers are involved in BRCA development and chemotherapy resistance [6]. MicroRNAs (miRNAs) are approximately 22 nucleotide RNAs that negatively regulate the expression of protein-coding genes by binding to their 3-untranslated regions (3'UTRs) [7]. Recently, next-generation sequencing (NGS) has allowed researchers to analyze miRNA-mRNA interactions in breast cancer [8]. Several studies have unveiled the regulatory functions of miRNAs in breast cancer. For instance, miR129-5p was demonstrated to stimulate Her-2-positive breast cancer sensitive to trastuzumab [9]. MiR-212-5p/miR-101 was validated to exert inhibitory influences on breast cancer in some studies [10,11], while miR-1246 promoted breast cancer and its drug resistance, [12] and miR-181a had dual regulatory roles in BRCA [13]. The molecular regulatory network of BRCA is quite complex, and thus, the specific molecular mechanisms of BRCA progression remain to be further elaborated.

Long noncoding RNAs (lncRNAs) are defined as RNA molecules greater than 200 nucleotides in length that lack an open reading frame capable of producing functional proteins [14]. Numerous studies have shown that lncRNAs are widely present in human cells and play crucial roles in various biological events, such as cell-cycle regulation, cell differentiation and tumorigenesis $[6,15]$. LncRNAs have been found to function as competing endogenous RNAs where they sponge miRNAs and regulate miRNA targets [16]. Wang et al. found that Huaier extract inhibited BRCA through lncRNA-H19/miR-675-5p [17]. In the present study, the dysregulated expression of the lncRNA KCNQ10T1 was found to be significantly associated with BRCA progression.

The KCNQ1 Opposite Strand/Antisense Transcript 1 (KCNQ10T1) gene, located at $11 \mathrm{p} 15.5$, is a member of the IncRNA group. KCNQ10T1 interacts with chromatin and regulates the transcription of multiple target genes through epigenetic modifications [18]. At present, few studies regarding its aberrant expression and function in cancers have been reported. Ren et al. revealed that KCNQ10T1 played an oncogenic role in regulating malignant behavior and chemoresistance of lung adenocarcinoma cells [19]. Sunamura et al. indicated that regulation of KCNQ10T1 lncRNA by $\beta$-catenin signaling might be involved in multiple processes of colorectal cancer development [20]. Gong et al. further hypothesized that KCNQ10T1/miR-370/CCNE2 may exert crucial influence on glioma cell progression, suggesting that this network may function as a novel therapeutic target [21]. Nevertheless, the underlying molecular mechanisms of KCNQ10T1 in BRCA have not yet been sufficiently explored.

The present study aims to investigate the role of KCNQ10T1 in BRCA. The effects of KCNQ10T1 on BRCA progression in vitro and in vivo and regulatory mechanisms between KCNQ10T1 and its downstream factors were elucidated. The KCNQ10T1/miR-145/CCNE2 axis was found to play a potential regulatory role in BRCA, which may contribute to the diagnosis and treatment of BRCA in the future. 


\section{Cellular Physiology Cell Physiol Biochem 2018;49:432-446 and Biochemistry Published \begin{tabular}{l|l} 
DOI: 10.1159/000492978 & (c) 2018 The Author(s). Published by S. Karger AG, Basel \\
www.karger.com/cpb
\end{tabular} \\ Feng et al.: LnCRNA KCNQ1OT1 Promotes Breast Cancer}

\section{Materials and Methods}

\section{Data collection and bioinformatics}

BRCA datasets including lncRNA, mRNA and miRNA data were downloaded from The Cancer Genome Atlas (TCGA). The IncRNA and mRNA profiles incorporated 91 pairs of cancerous and adjacent breast tissues, while the miRNA profile included 84 pairs of cancerous and adjacent breast tissues. R software and the Morpheus online application were used to produce volcano plots and heat maps of differentially expressed genes. Cut-off values for IncRNA and mRNA analysis were set at $\mid \log 2$ (fold change) $\mid>2$ and $\mathrm{P}<0.00001$ for the limma package, whereas those for miRNA analysis were set at $\mid \log 2$ (fold change) $\mid>1$ and $P<0.01$. The KEGG pathway-related gene profile was downloaded from the GSEA database. StarBase v2.0 was used to predict the relationships between IncRNAs and miRNAs as well as between miRNAs and mRNAs. In addition, the expression data of miR-145 and CCNE2 were derived from StarBase v2.0.

\section{Tissue samples and cell lines}

Eighteen pairs of breast cancer and adjacent tissues were collected from Zhejiang Cancer Hospital, China. Sixty-three pairs of breast cancer tissues were obtained from Zhejiang Cancer Hospital between December 2015 and June 2017. All tissues were pathologically confirmed to be either cancerous or healthy. They were kept in liquid nitrogen for subsequent experiments. The present research was approved by Zhejiang Cancer Hospital and the clinical information of sixty-three female patients was listed in Table 1. The normal human mammary gland cell line Hs 578Bst as well as cancerous human mammary gland cell lines SK-BR-3, BT-20 and MX-1 were purchased from the BeNa Cell Collection (Beijing, China). MCF7 and HEK293T cells were cultured in the lab. All cell lines were cultured in L-15 media containing 10\% fetal bovine serum (FBS).

\section{Cell transfection}

Single-stranded siRNAs of KCNQ10T1 and CCNE2 were purchased from Thermo Fisher Scientific and were transfected into cells with the siRNA-Meta reagent (GenePharma, Shanghai, China). MiR-145 mimics and inhibitors were procured from GenePharma and transfected by using Lipofectamine 2000. PcDNA3.1 plasmids from the lab were used to construct CCNE2 overexpression vectors with BamHI and XhoI. The transfection concentrations for siRNA (sequence capable of KCNQ10T1 knockdown), siRNA-C (sequence capable of CCNE2 knockdown), mimics and inhibitors were $50 \mathrm{nM}, 60 \mathrm{nM}, 10$ $\mathrm{nM}$ and $5 \mathrm{nM}$, respectively. Primer sequences were exhibited in Table 2.

\section{Dual luciferase reporter gene assay}

PmirGLO plasmids were purchased form Youbio (Changsha, Hunan, China). The amplified sequences of KCNQ10T1 and CCNE2 were cloned into pmirGLO plasmids. The corresponding amplified mutated sequences were inserted into the plasmids to construct vectors of interest along with the restriction endonuclease sites ScaI and XbaI. The primers for recombined vectors were displayed in Table 2. The constructed IncRNA and gene overexpression vectors together with miR-145 mimics were transfected into HEK293T cells. The cells in the control group were treated with transfection reagents. Cells in the negative control (NC)
Table 1. Clinical information for the 63 female breast cancer patients

\begin{tabular}{lcc}
\hline Variant & \multicolumn{2}{c}{ Samples } \\
\hline Age & $>50$ & $<50$ \\
& 38 & 25 \\
Tumor size & $>5 \mathrm{~cm}$ & $<5 \mathrm{~cm}$ \\
& 34 & 29 \\
Tumor count & single & multiple \\
& 19 & 44 \\
Tumor stage & $\mathrm{I}+\mathrm{II}$ & $\mathrm{III}+\mathrm{IV}$ \\
& 25 & 38 \\
\hline
\end{tabular}

Table 2. Sequences used in the transfection experiments. siRNAs were used for silencing KCNQ10T1, siRNA-Cs were used for silencing CCNE2, mimics was used for overexpressing miR-145, and inhibitor was used for suppressing miR-145. CCNE2 CDS-F and CCNE2 CDS-R were the primers for the recombined CCNE2 overexpressed vector. CCNE2 3'UTR-F and CCNE2 3'UTR-R were used to recombine the biluciferase reporter vector carrying the sequence of CCNE2 3'UTR. KCNQ10T1-F and KCNQ10T1-R were used to establish the wild-type KCNQ10T1 biluciferase reporter vector. shRNA-1 and shRNA-3 were transformed from siRNA-1 and siRNA-3 and were used in the animal experiments

\begin{tabular}{|c|c|}
\hline Name & Primer sequences $\left(5^{\prime} \rightarrow 3^{\prime}\right)$ \\
\hline SiRNA-1 & $\begin{array}{l}\text { gccaauggauagagagcaa } \\
\end{array}$ \\
\hline SiRNA-2 & ggauagagagcaagggaaa \\
\hline siRNA-3 & ccuggaggugauaaauuaa \\
\hline Mimics & gtccagttttcccaggaatccct \\
\hline Inhibitors & agggattcctgggaaaactggac \\
\hline SiRNA-C1 & cccagauaauccaggccaa \\
\hline siRNA-C2 & ccuucaccuuugccugauu \\
\hline SiRNA-C3 & gcuugcagugaagaggaua \\
\hline CCNE2 CDS-F & GGATTC atgtcaagacgaagta \\
\hline CCNE2 CDS-R & CTCGAG ttagtgtttcctggtggt \\
\hline CCNE2 3'UTR-F & AGTACT agaagataactaagc \\
\hline CCNE2 3'UTR-R & ggccTCTAGA ttttaaacaatgggcta \\
\hline KCNQ10T1-F & AGTACTgaccccgctgcacggctgt \\
\hline KCNQ10T1-R & TCTAGAgggaacatgatcctct \\
\hline shRNA-1-top & caccgccaatggatagagagcaaaacgttgctctctatccattggc \\
\hline shRNA-1-bottom & aaaagccaatggatagagagcaacgttttgctctctatccattggc \\
\hline shRNA-3-top & caccgcctggaggtgataaattaaaacgttaatttatcacctccagg \\
\hline shRNA-3-bottom & aaaacctggaggtgataaattaacgttttaatttatcacctccaggc \\
\hline
\end{tabular}




\section{Cellular Physiology Cell Physiol Biochem 2018;49:432-446 \begin{tabular}{l|l|l} 
DOI: 10.1159/000492978 & $\begin{array}{l}\text { O } 2018 \text { The Author(s). Published by S. Karger AG, Basel } \\
\text { www.karger.com/cpb }\end{array}$
\end{tabular} \\ Feng et al.: LncRNA KCNQ10T1 Promotes Breast Cancer}

subgroup were transfected with the constructed lncRNA and gene overexpression vectors together with miR-145 mimic control (GenePharma).

\section{QRT-PCR}

Total RNA was extracted using the miRCURY RNA isolation kit (\#300110, QIAGEN, Hilden, Germany) for the detection and quantification of miRNA, IncRNA and mRNA of tissues and cells. The isolated RNA was first converted to cDNA through Access RT-PCR System (\#A1250, Promega, Madison, WI, USA). SYBR green assays were used to analyze the expression of miR-145 (ExiLENT SYBR green master mix, \#203421, QIAGEN), CCNE2 (ExiLERATE LNA qPCR, \#303410, QIAGEN) and KCNQ10T1 (ExiLERATE LNA qPCR, \#303410, QIAGEN).

GAPDH was the internal control gene for KCNQ10T1 and CCNE2, while U6 was the endogenous control gene for miR-145. Primer information was presented in Table 3.

\section{Western blot}

Forty-eight hours after cell transfection, the transfection efficiency was confirmed. The cells were lysed using RIPA buffer. The supernatant was collected, and $40 \mu \mathrm{g}$ was resolved by using SDS-PAGE (TGX Gels, Bio-Rad Laboratories Inc., Hercules, CA, USA). The resolved proteins were then transferred onto PVDF membranes. Antibodies including anti-CCNE2 (\#ab32103), anti-GAPDH (\#128915) and HRP-IgGs (\#6721) were applied to membranes. After the membranes had been washed three times, the signal was captured using West Dura. Protein levels were quantified using ImageJ software.

\section{MTT assay}

The cultured cells were harvested by centrifugation and then resuspended at $1 \times 106$ per ml. Then, 100 $\mu \mathrm{l}$ of cell suspension was placed into a microtiter plate in triplicate. Three wells of medium alone were used as the control. After $48 \mathrm{~h}$ of culture, each well was supplemented with $10 \mu \mathrm{l}$ MTT reagent and incubated for another $3 \mathrm{~h}$ or longer until the purple precipitate was visible under a microscope. Then, $100 \mu \mathrm{l}$ of detergent reagent was added to each well before a 2 -h incubation in the dark. Finally, the optical absorbance of each well was observed at $450 \mathrm{~nm}$ in a microtiter plate reader. All reagents were purchased from Biomart (Beijing, China).

\section{Colony formation assay}

The cultured cells were digested using $4 \mathrm{ml}$ of $0.25 \%$ trypsin and then seeded in 6-well plates (Thermo Fisher Scientific) in triplicate, followed by a seven-day incubation. When the cells formed visible colonies, the medium was removed, and 2-3 $\mathrm{ml}$ of fixation solution was added to the plates. Five minutes later, the fixation solution was discarded, and $0.5 \%$ crystal violet (Sigma-Aldrich, Shanghai, China) solution was added and incubated with cells for $2 \mathrm{~h}$. Subsequently, the crystal violet was removed, and the plates were air-dried. A few days later, the colonies were observed under a microscope (TS100, Nikon Eclipse, Japan).

\section{Transwell assay}

A transwell assay was conducted to examine the migration and invasion capabilities of cells. The transwell compartments were prepared by adding $3 \mathrm{ml}$ of DMEM with $0.5 \%$ FBS along with transwell inserts into the lower compartment. Then, $1 \times 105$ cells were added onto the inserts and incubated for $12 \mathrm{~h}$ before transfection, which allowed the cells to migrate toward the underside of the insert membrane. The inserts were then taken out, and non-migratory cells were removed from the upper side of the membrane. Cells on the lower side of the inserts were quickly fixed with $5 \%$ glutaraldehyde for 10 min and stained with $1 \%$ crystal violet in $2 \%$ ethanol for $20 \mathrm{~min}$. Excess crystal violet was removed by immersing the inserts in $\mathrm{ddH} 2 \mathrm{O}$ for 3 to 5 seconds. The migratory cells were counted under a microscope. For the cell invasion assay, Matrigel was added to the inserts, and the number of invasive cells was detected and analyzed after $48 \mathrm{~h}$. 


\section{Cellular Physiology Cell Physiol Biochem 2018;49:432-446 \begin{tabular}{ll|l} 
and Biochemistry & $\begin{array}{l}\text { DOI: 10.1159/000492978 } \\
\text { Published online: 29 August, } 2018\end{array}$ & $\begin{array}{l}\text { (c) } 2018 \text { The Author(s). Published by S. Karger AG, Basel } \\
\text { www.karger.com/cpb }\end{array}$ \\
\hline
\end{tabular} \\ Feng et al.: LnCRNA KCNQ1OT1 Promotes Breast Cancer}

Cell apoptosis and cell cycle analysis

Cells were seeded in a 24-well plate after transfection with the corresponding group parameters and incubated for $48 \mathrm{~h}$. The supernatant and adherent cells were collected and resuspended. After $500 \mu \mathrm{l}$ of the cell suspension was incubated with $2 \mu \mathrm{l}$ of Annexin $(1 \mathrm{mg} / \mathrm{ml})$ and $2 \mu \mathrm{l}$ of propidium iodide $(1 \mathrm{mg} /$ ml) (CA1020, Solarbio, Beijing, China), the cells were analyzed using a flow cytometer. Annexin-positive and propidium iodide-positive cells were considered apoptotic. Cell cycle analysis was performed using propidium iodide (C1052, Beyotime, ShangHai, China) with the BD FACSCalibur Flow Cytometry System (BD Pharmingen).

\section{Xenograft assay}

After transforming the sequences of siRNA-1 and siRNA-3 against lncRNA KCNQ10T1 to shRNA-1 and shRNA-3 (Table 2), stable knockdown in the breast cancer cell line MCF7 was achieved. Stably transfected cells were selected for more than 3-6 months for resistances provided by the vectors to confirm expression stability. Afterwards, $1 \times 106$ stably transfected cells were injected into the flanks of female BALB/c-nude mice (5-6 weeks old, $n=6$ in each group) that were purchased from Cavens Lab Animal Ltd. (Changzhou, Jiangsu, China). For the survival experiment, only the survival ratios were recorded after injections. To measure tumor size, $1 \times 106$ cells were injected into fresh mice ( $n=5$ in each group), and tumor growth was continuously monitored for 4 weeks. At the end of the fourth week, all mice were euthanized, and tumors were removed for further analysis.

\section{Statistical analysis}

All data analyses were conducted with GraphPad Prism 6.0. $\mathrm{P}<0.05$ was considered statistically significant. The above experiments were performed at least three times. Data were presented as the mean \pm standard deviation. Nonparametric Wilcoxon matched-pairs was applied to the analysis of clinical samples. The unpaired Student t-test and one-way ANOVA multiple comparisons test were used to compare the data of two groups and multiple groups, respectively. Kaplan-Meier survival analysis and log rank test were utilized to estimate the survival rates of patients. Spearman rank correlation coefficients ( $r$ ) were determined to analyze the correlation between gene expression.

\section{Results}

\section{KCNQ10T1 expression in cancerous and healthy breast tissues and cell lines}

In our examination of the expression values of IncRNAs in 91 paired TCGA breast cancer samples, we set the screening criteria to $\mid \log 2$ (fold change) $\mid>2$ and $\mathrm{P}<0.00001$ to identify the differentially expressed lncRNAs. The top 20 significantly differentially expressed lncRNAs, including 10 upregulated and 10 downregulated lncRNAs, were selected for the heatmap (Fig. $1 \mathrm{~A}-1 \mathrm{~B}$ ), and the log2 (fold change) of each are presented in Table 4 along with the $\mathrm{P}$ values. Among these IncRNAs, KCNQ10T1 was the most highly expressed in tumor tissues. The Kaplan-Meier curve indicated that higher expression levels of KCNQ10T1 corresponded to poorer patient prognoses (Fig. 1C). In addition, we also verified that the expression of KCNQ10T1 was much higher in cancerous breast tissues $(n=18)$ and cell lines than in normal adjacent breast tissues and the normal breast cell line Hs 578Bst (Fig. 1D - 1E). Since MCF7 and SKBR-3 cell lines had the highest level of KCNQ10T1, they were chosen for subsequent analysis.

Table 4. Microarray analysis results of top 10 highest and lowest expressed lncRNAs. DEGs means differentially expressed genes; $\mathrm{p}$ value was calculated by $\mathrm{t}$ test, and $\mathrm{p}$ adj was obtained by $p$ value normalized by Benjamini-Hochberg

\begin{tabular}{lllllll}
\hline DEGs & baseMean & log2FoldChange & lfcSE & stat & p value & p adj \\
\hline HSD52 & 15.0031 & -4.4779 & 0.358371 & -12.4951 & $7.94 \mathrm{E}-36$ & $2.30 \mathrm{E}-34$ \\
ADIPOQ-AS1 & 34.05275 & -4.44037 & 0.374908 & -11.8439 & $2.31 \mathrm{E}-32$ & $5.16 \mathrm{E}-31$ \\
TRHDE-AS1 & 857.9422 & -4.19735 & 0.356984 & -11.7578 & $6.44 \mathrm{E}-32$ & $1.42 \mathrm{E}-30$ \\
LINC01070 & 16.94053 & -4.17878 & 0.33061 & -12.6396 & $1.28 \mathrm{E}-36$ & $3.91 \mathrm{E}-35$ \\
LINC01028 & 17.33737 & -4.15198 & 0.305929 & -13.5717 & $5.89 \mathrm{E}-42$ & $2.74 \mathrm{E}-40$ \\
ALDH1 L1-AS2 & 82.72427 & -4.1296 & 0.337929 & -12.2203 & $2.42 \mathrm{E}-34$ & $6.53 \mathrm{E}-33$ \\
LINC01697 & 165.0766 & -4.08907 & 0.255086 & -16.0302 & $7.86 \mathrm{E}-58$ & $1.06 \mathrm{E}-55$ \\
LINC00645 & 15.13221 & -3.97665 & 0.503886 & -7.89196 & $2.97 \mathrm{E}-15$ & $2.19 \mathrm{E}-14$ \\
LINC01230 & 175.8771 & -3.90401 & 0.352703 & -11.0688 & $1.78 \mathrm{E}-28$ & $3.33 \mathrm{E}-27$ \\
LINC00968 & 168.5177 & -3.90247 & 0.23381 & -16.6908 & $1.53 \mathrm{E}-62$ & $3.17 \mathrm{E}-60$ \\
BMPR1B-AS1 & 42.48069 & 5.086179 & 0.39358 & 12.92284 & $3.35 \mathrm{E}-38$ & $1.14 \mathrm{E}-36$ \\
C5orf66-AS1 & 14.0561 & 5.307987 & 0.42934 & 12.36313 & $4.14 \mathrm{E}-35$ & $1.15 \mathrm{E}-33$ \\
LINC00922 & 50.74588 & 5.343078 & 0.233602 & 22.87254 & $8.72 \mathrm{E}-116$ & $1.18 \mathrm{E}-112$ \\
WT1-AS & 42.01392 & 5.38315 & 0.391046 & 13.76602 & $4.08 \mathrm{E}-43$ & $2.08 \mathrm{E}-41$ \\
LINC01561 & 17.69844 & 5.406718 & 0.29019 & 18.63163 & $1.78 \mathrm{E}-77$ & $9.60 \mathrm{E}-75$ \\
VSTM2A-OT1 & 11.13805 & 5.528255 & 0.667342 & 8.28399 & $1.19 \mathrm{E}-16$ & $9.91 \mathrm{E}-16$ \\
KCNQ10T1 & 27.54375 & 6.536375 & 0.311557 & 20.97972 & $1.00 \mathrm{E}-97$ & $6.77 \mathrm{E}-95$ \\
LINC01614 & 306.0533 & 6.571161 & 0.240332 & 27.34207 & $1.34 \mathrm{E}-164$ & $3.62 \mathrm{E}-161$ \\
LINC00052 & 80.38016 & 7.377199 & 0.587954 & 12.54725 & $4.12 \mathrm{E}-36$ & $1.23 \mathrm{E}-34$ \\
DSCAM-AS1 & 670.4787 & 8.079505 & 0.53689 & 15.0487 & $3.52 \mathrm{E}-51$ & $3.52 \mathrm{E}-49$ \\
\hline
\end{tabular}


Fig. 1. KCNQ10T1 displayed increased expression in breast cancer tissues and cells. (A) TCGA results showed differentially expressed IncRNAs in BRCA samples. KCNQ10T1 was overexpressed in cancerous breast tissues. Expression levels can be read with the color bar. (B) Volcano plot showed gene expression profiles in BRCA samples with the cutoff of $\mid \log 2$ (fold change) $\mid>2$ and $\mathrm{P}<0.00001$. (C) The Kaplan-Meier curve reflected that increased KCNQ10T1 expression predicted worse overall survival outcome. (D) KCNQ10T1 expression was higher in 18 paired cancer tissue samples. (E) KCNQ10T1 expression was higher in BT20, SK-BR-3, MX-1 and MCF7 cells. ${ }^{*} \mathrm{P}<0.05$, compared with the normal breast cell Hs 578Bst.

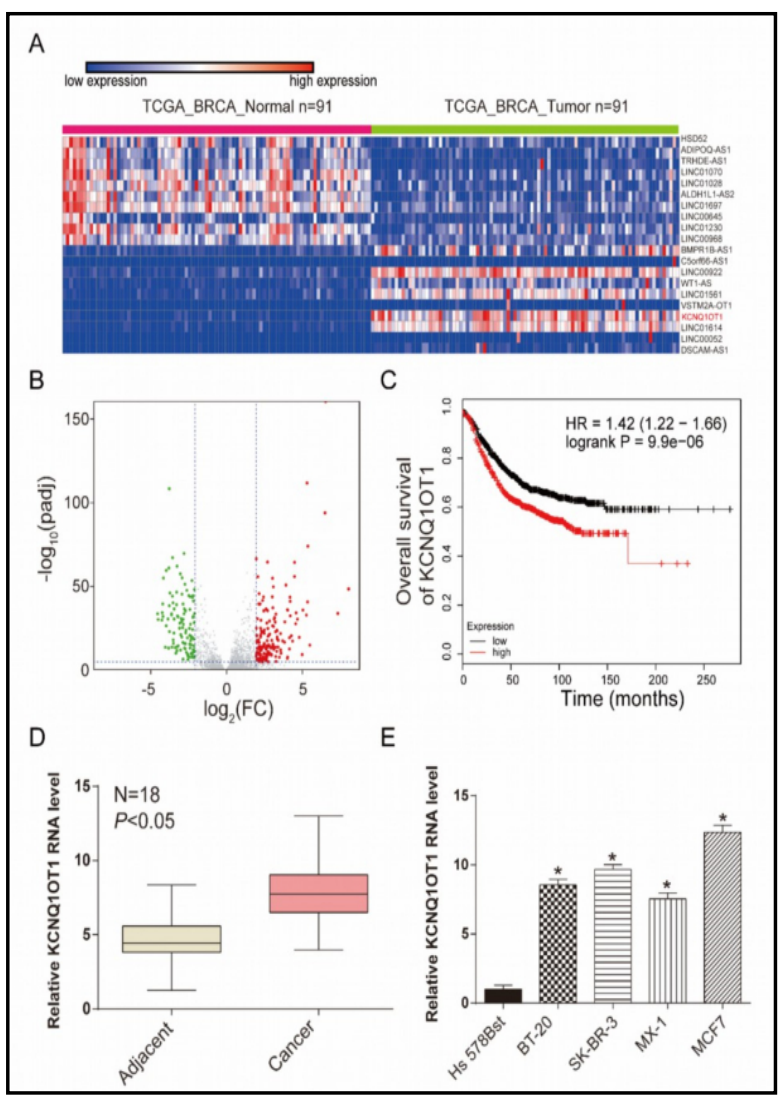

Fig. 2. KCNQ10T1 affects MCF7 cell viability, apoptosis, mobility and cell cycle. (A) KCNQ10T1specific siRNAs effectively reduced KCNQ10T1 expression, with siRNA-1 showing the highest efficiency. (B) In the MTT assay, KCNQ10T1 knockdown inhibited cell viability. (C) Annexin V/PI double-staining showed increased cell apoptosis ratios after KCNQ10T1 knockdown. (D) PI staining showed that KCNQ10T1 knockdown caused cell cycle arrest. (E) In the transwell assay, KCNQ10T1 knockdown inhibited cell migration and invasion. ${ }^{*} \mathrm{P}<0.05$, compared with the NC group.

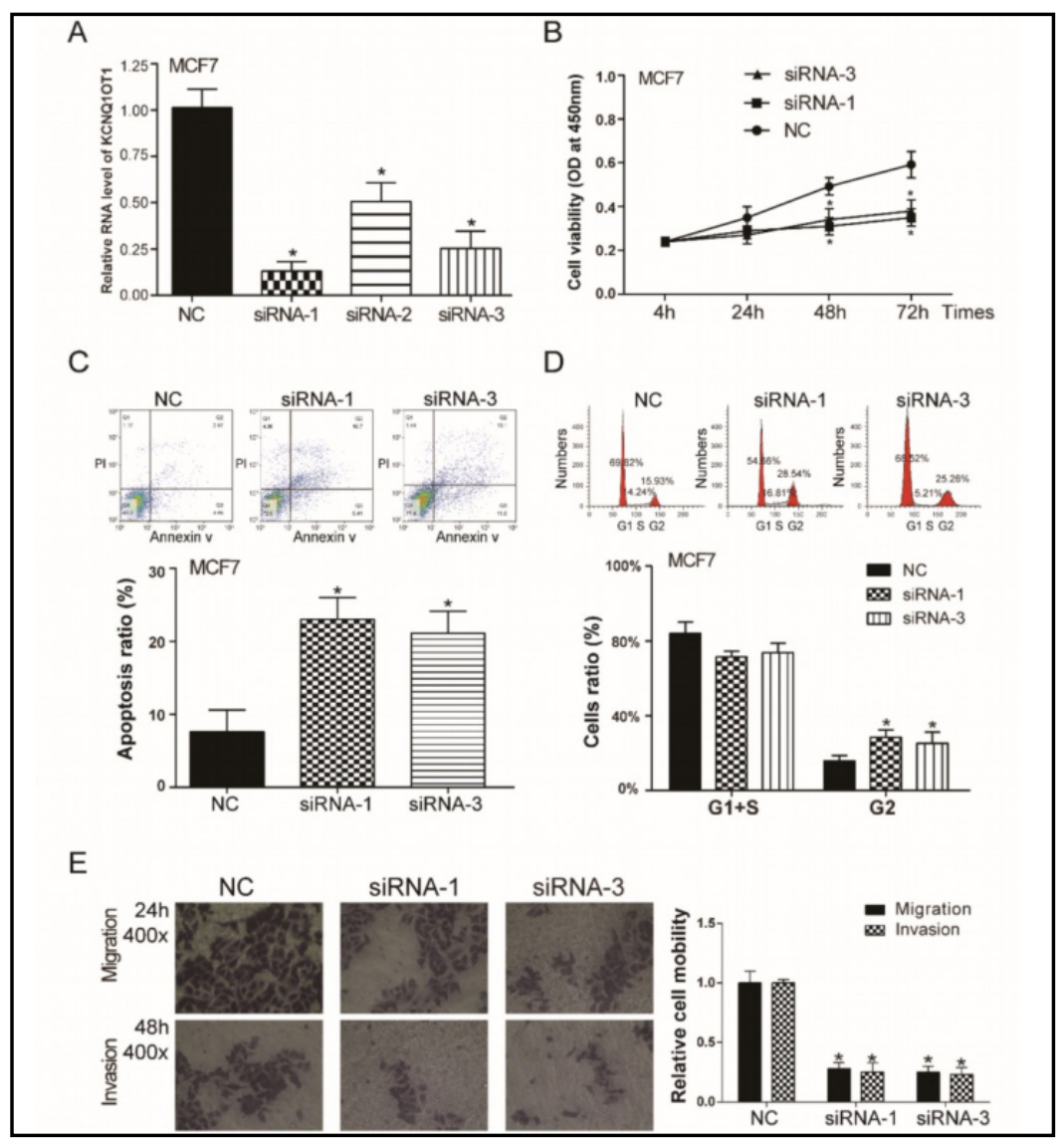


Fig. 3. Cell proliferation, apoptosis, cell mobility, and cell cycle analyses in SKBR-3 cells after KCNQ10T1 knockdown. (A) KCNQ10T1 siRNAs (siRNA1-3) were used to knockdown KCNQ10T1. (B) KCNQ10T1 knockdown inhibited cell proliferation. (C) Increasing apoptosis ratios were seen in the KCNQ10T1 knockdown group. (D) KCNQ10T1 knockdown resulted in cell cycle arrest at the G2 stage. (E) Inhibition of KCNQ10T1 impeded cell migration and invasion. * $\mathrm{P}$ $<0.05$, compared with the NC group.

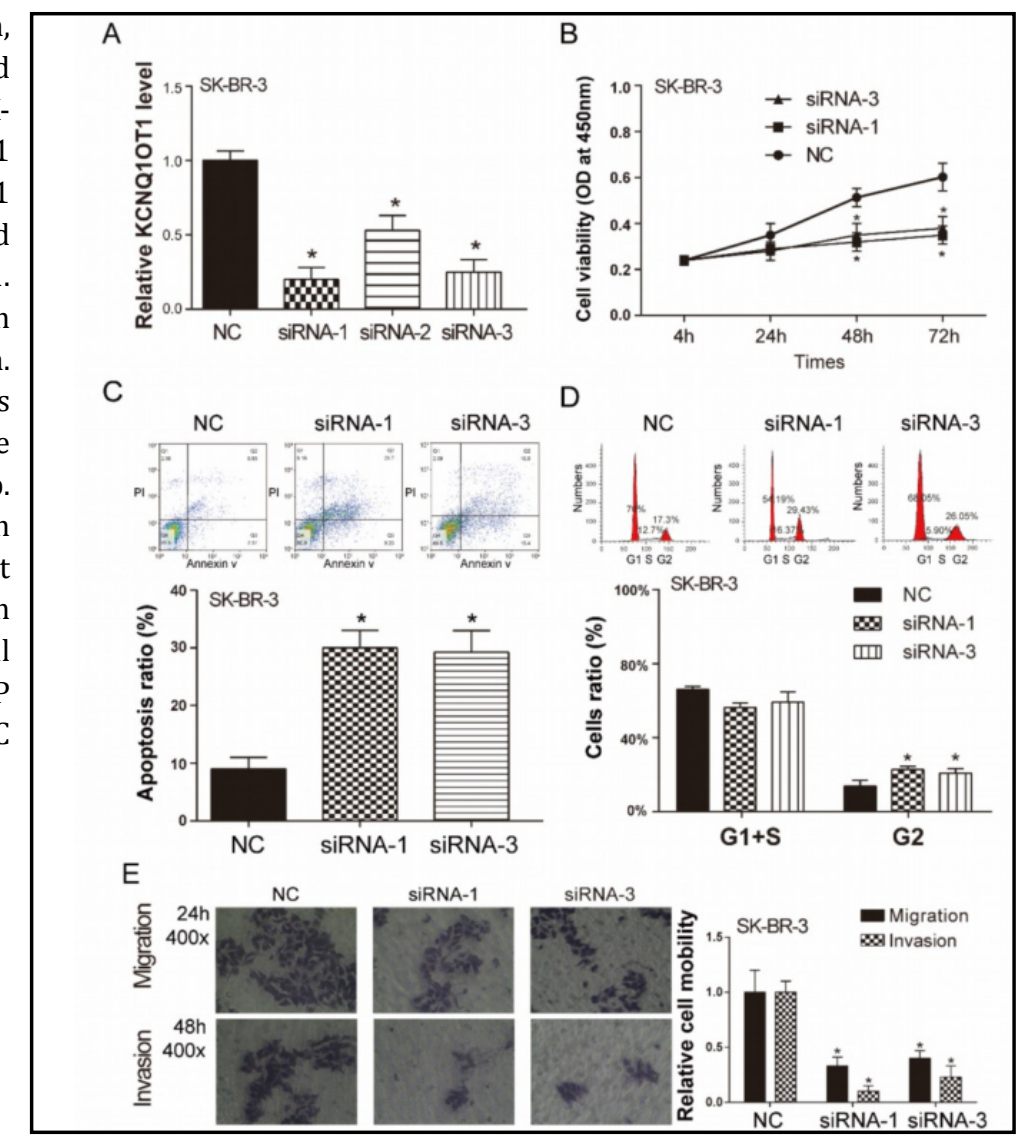

Fig. 4. MiR-145 expression was reduced in breast cancer tissues and cells. (A) Volcano plot showed differentially expressed miRNAs in 84 paired breast cancer tissues with the cutoff of $\mid \log 2$ (fold change) $\mid>1$ and $\mathrm{P}<0.01$. Red dots represent genes with higher expression, while green indicates lower expression. (B) The intersection of predicted KCNQ10T1 target miRNAs and diff_miRNAs of the TCGA data identified miR-383 and miR-145. (C) A heatmap showed the top 20 miRNAs differentially expressed in 84 paired normal and tumor samples, with both miR-383 and miR-145 having decreased expression in cancer tissues. (D) The Kaplan-Meier plot revealed that higher miR-145 expression predicted longer survival rates. (E) StarBase v2.0 displayed lower expression of miR-145 in breast cancer. (F) MiR-145 expression was lower in 18 cancer samples. (G) MiR145 expression was lower in breast cancer cells BT-20, SK-BR-3, MX-1 and MCF7 than in the normal breast cell line Hs 578Bst. * $\mathrm{P}<0.05$, compared with the normal breast cell line Hs 578Bst.

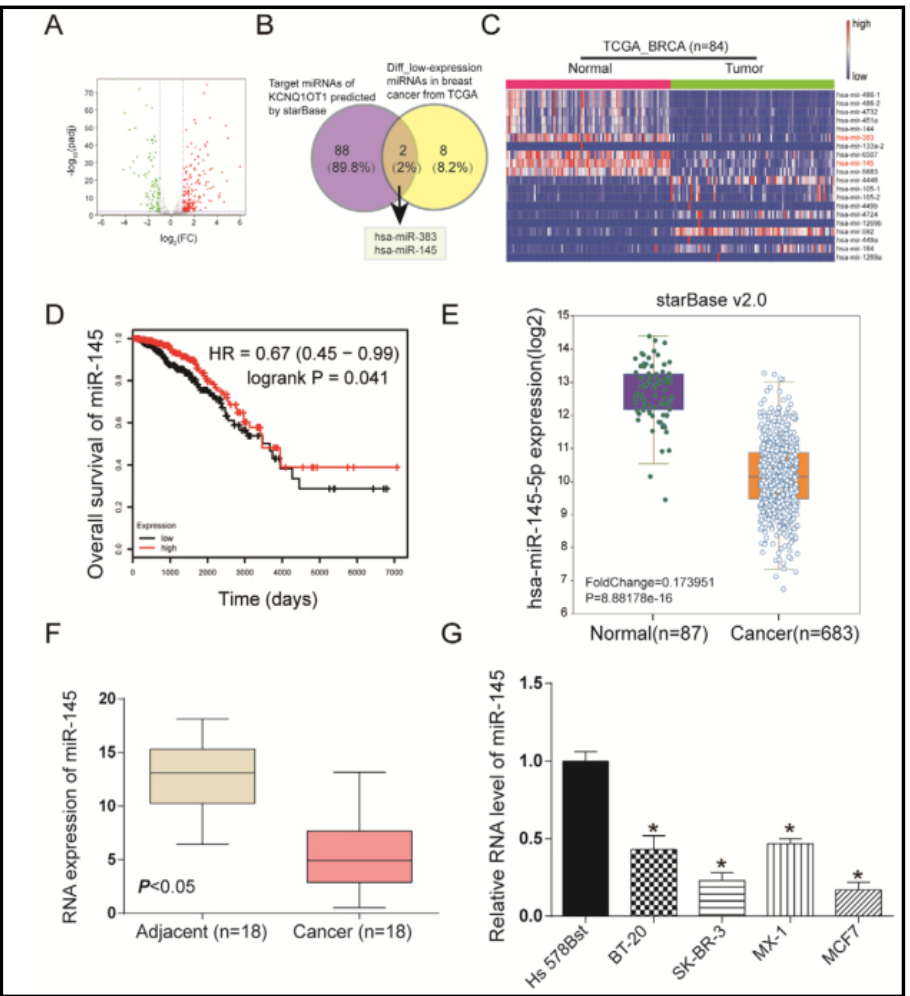
KARGER 
Fig. 5. CCNE2 showed higher expression in breast cancer tissues and cells. (A) All differentially expressed genes from 91 paired breast samples in the TCGA dataset are shown in the volcano plot with the cutoff of $\mid \log 2$ (fold change) $\mid>2$ and $\mathrm{P}<0.00001$. (B) CCNE2, FN1 and PPARG were derived from the intersections of the KEGG pathway in cancer dataset, predictive target genes of miR-145 dataset and diff genes of TCGA dataset. (C) CCNE2 expression was higher in 91 TCGA patient samples. (D) CCNE2 mRNA expression was higher in the StarBase v2.0 database. (E) CCNE2 mRNA expression in BT-20, SK-BR-3, MX-1 and MCF7 was higher than in the normal breast cell line Hs 578Bst. * $\mathrm{P}<0.05$, compared with the normal breast cell line Hs 578Bst.

Fig. 6. KCNQ10T1 affected the expression of miR-145/ CCNE2. (A-C) Spearman rank correlation plot analyses showed a negative correlation between KCNQ10T1 and miR-145 with a correlation coefficient (r) of 0.6972. CCNE2 was negatively correlated with miR-145 expression with $\mathrm{r}=0.8800$, while KCNQ10T1 was positively correlated with CCNE2 expression with $r=0.5149$. $N$ represented the number of clinical samples, and all $P$ values showed statistical significance. (D-E) KCNQ10T1 siRNAs inhibited CCNE2 mRNA expression and CCNE2 protein expression in MCF7 cells. (F) Knockdown of KCNQ10T1 promoted the expression of miR-145 in MCF7 cells. * Implies $\mathrm{P}<0.05$ compared with the $\mathrm{NC}$ group.
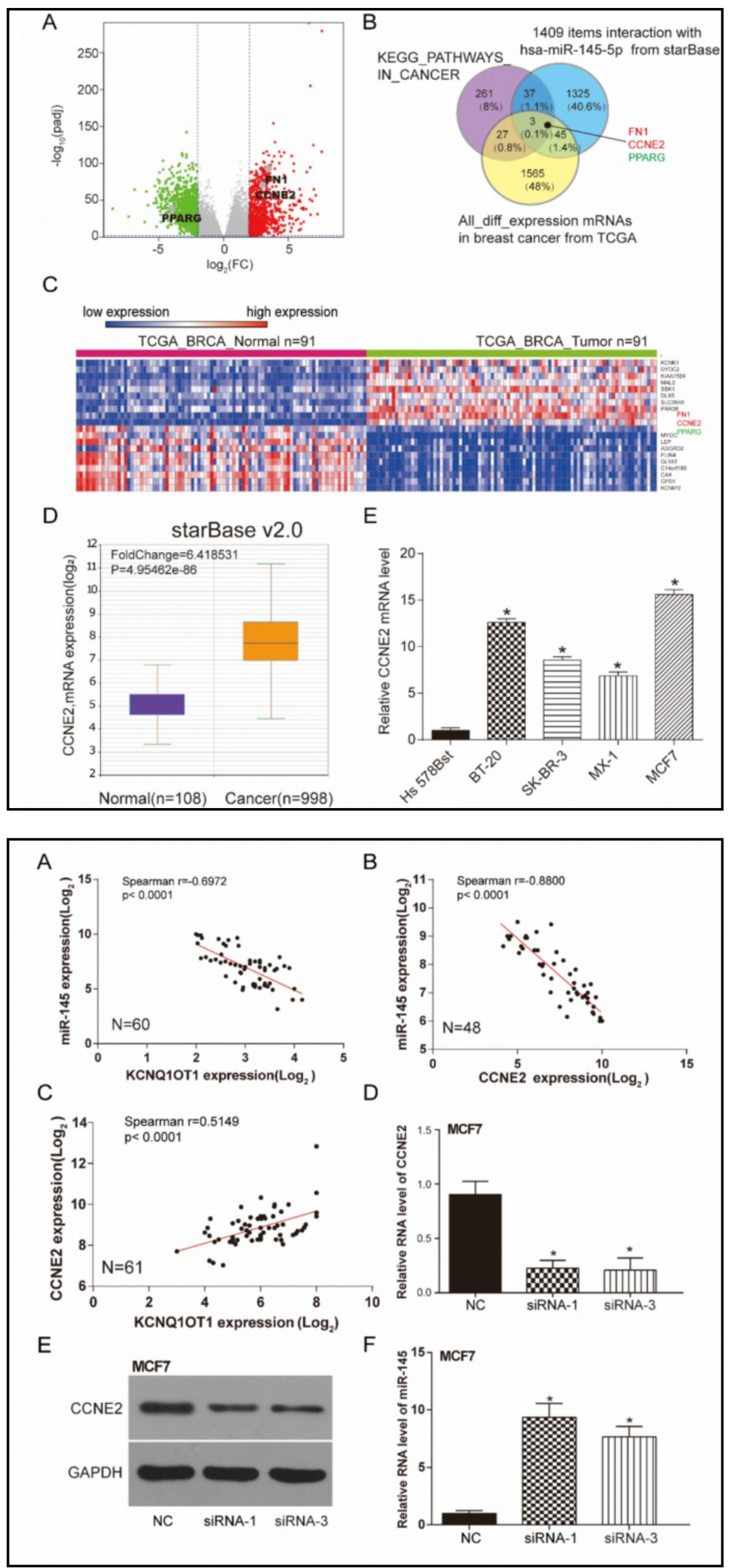


\section{Cellular Physiology Cell Physiol Biochem 2018;49:432-446 and Biochemistry DOI: 10.1159/000492978 \begin{tabular}{l|l} 
O 2018 The Author(s). Published by S. Karger AG, Basel \\
wwwwkargercom/cpb
\end{tabular}

Fig. 7. The target relationship of KCNQ10T1/ miR-145/CCNE2. MiR-145 mimics inhibited luciferase activity of the wild-type KCNQ10T1 (A) and wildtype CCNE2 vector (B). (C) MiR-145 expression was increased by miR-145 mimics and suppressed by miR-145 inhibitor. (D) siRNA-C1-C3 suppressed CCNE2 expression, and the CCNE2 vector elevated CCNE2 expression. (Eand F) CCNE2 mRNA and protein expression were detected after transfection. CCNE2 knockdown and miR-145 overexpression suppressed CCNE2 expression, while siRNA-C1 + miR-145 inhibitor and siRNA-C1 + CCNE2 overexpression had no significant influence on CCNE2 expression. * $\mathrm{P}$ $<0.05$, compared with the NC group.

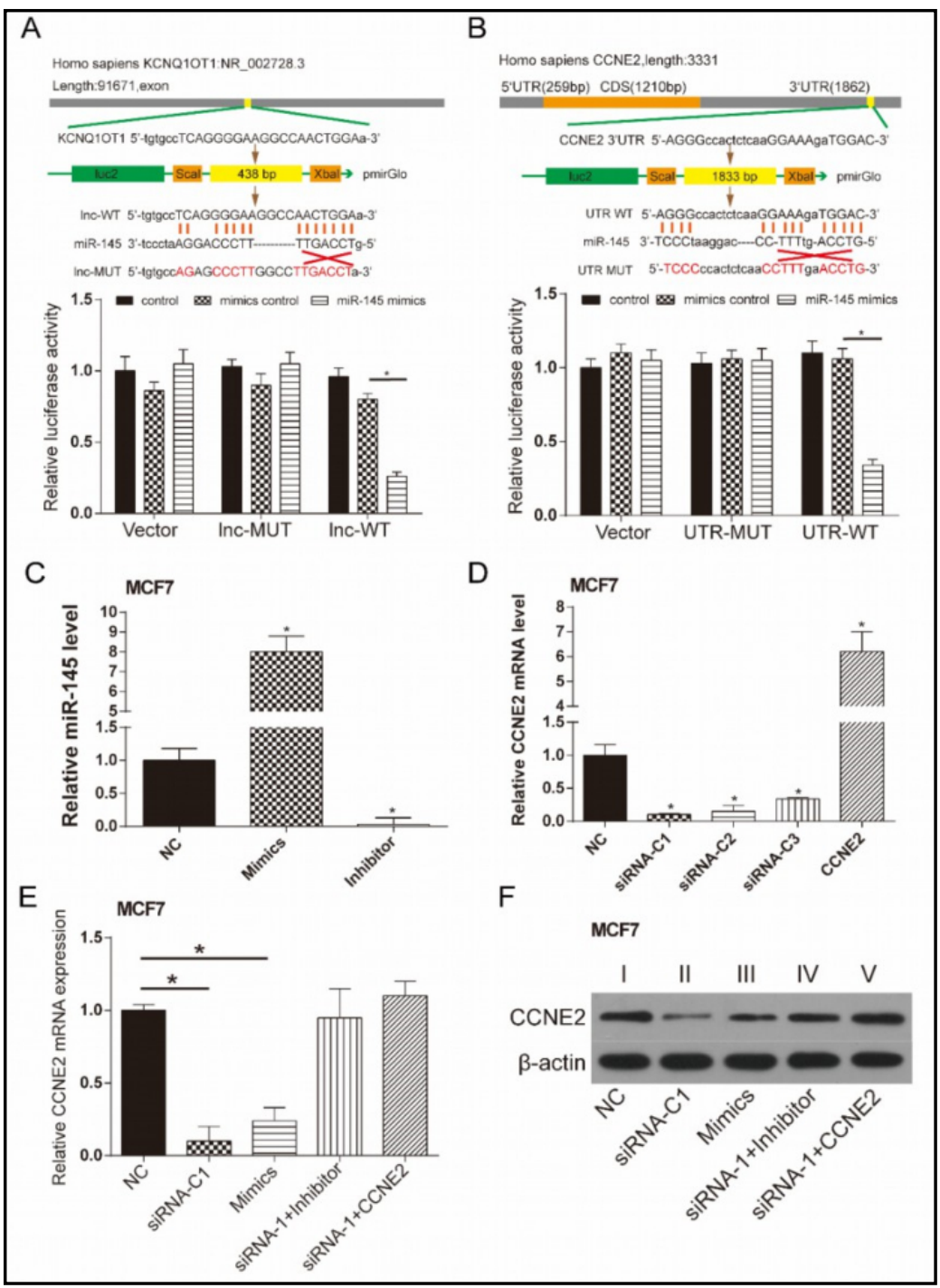

Effects of KCNQ1OT1 on MCF7 and SK-BR-3 cell activities

We confirmed the knockdown efficiency of three siRNAs to KCNQ10T1 in MCF7 and SK-BR-3 cell lines. siRNA-1 and siRNA-3 showed the best knockdown efficiency in both cell lines (Fig. 2A and Fig. 3A). The transfection of siRNA-1 and siRNA-3 successfully inhibited viability, migration and invasion, promoted apoptosis and significantly induced cell cycle arrest at the G2 phase (Fig. 2B - 2E). Similar trends were found in the breast cancer SK-BR-3 cell line (Fig. 3).

\section{MiR-145 and CCNE2 expression in cancerous and healthy breast tissues and cell lines}

Eighty-four paired TCGA breast cancer data sets were analyzed for differentially expressed miRNAs (Fig. 4A), and the top 20 significantly differentially expressed miRNAs are presented in a heatmap (Fig. 4C). Through intersecting the predicted target miRNA dataset of starBase v2.0 with the differentially expressed miRNA dataset of TCGA, we discovered two shared miRNAs, miR-383 and miR-145, in both datasets (Fig. 4B). Using a large cohort of TCGA data with low miR-145 patients $(n=460)$ and high miR-145 patients $(n=615)$, we chose to evaluate the correlation between BRCA patients' survival outcome and the expression level of miR-145. Kaplan-Meier results indicated that lower expressions of miR-145 corresponded to poorer overall survival outcomes in BRCA patients (Fig. 4D). Expression data for miR- 
Fig. 8. Regulation of KCNQ10T1/ miR-145/CCNE2 affected MCF7 proliferation and mobility. (A) CCNE2 knockdown and miR145 overexpression inhibited proliferation. (B) CCNE2 knockdown and miR-145 overexpression reduced migration and invasion. Cells were divided into NC (I), siRNA-C1 (II), mimics (III), siRNA-1 + miR-145 inhibitor (IV) and siRNA-1 + CCNE2 (V) groups. ${ }^{*} \mathrm{P}<0.05$, compared with the NC group.

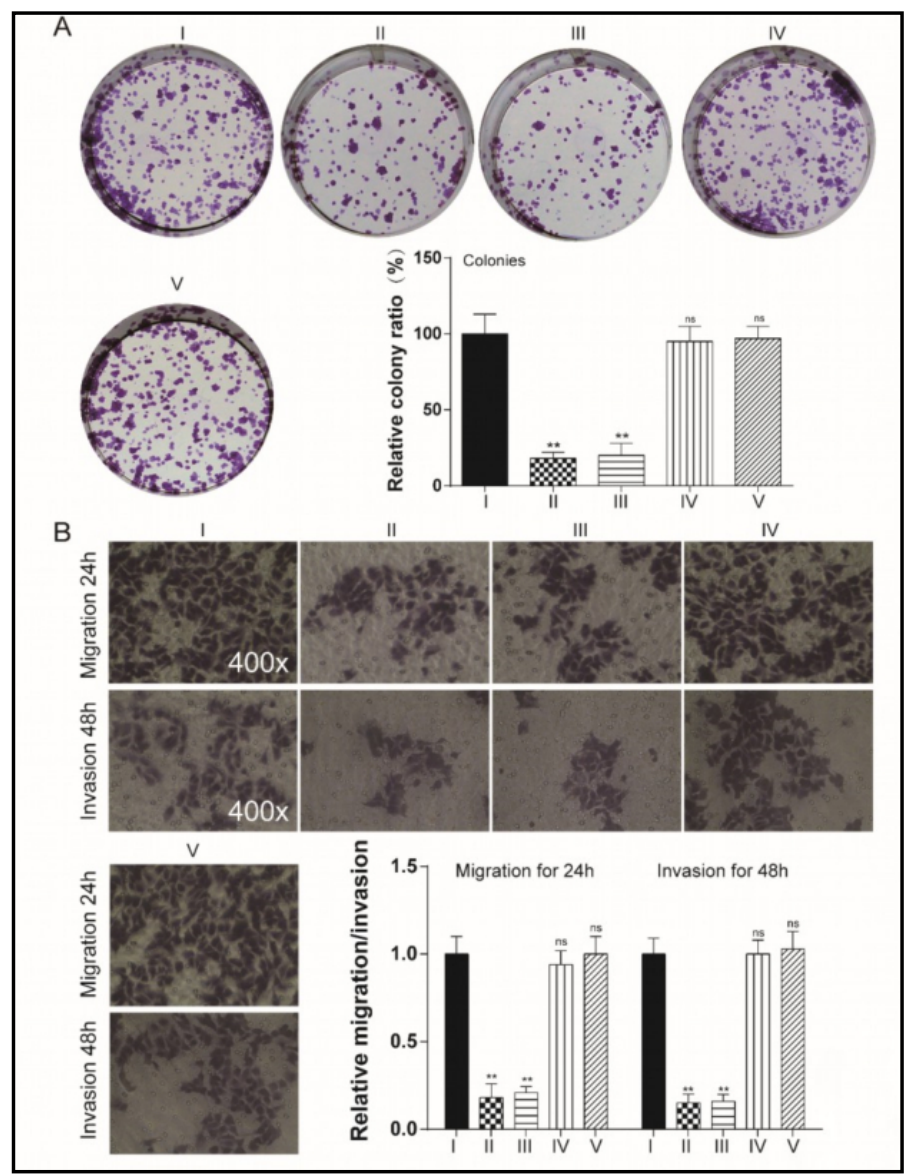

Fig. 9. Knockdown of CCNE2 promoted MCF7 cell apoptosis and G2-stage cell cycle arrest. (A-B) CCNE2 knockdown and miR145 overexpression promoted cell apoptosis and suppressed the cell cycle. The groups were divided into $\mathrm{NC}$ (I), siRNA-C1 (II), mimics (III), siRNA-1 + miR145 inhibitor (IV) and siRNA-1 + CCNE2 (V). * $\mathrm{P}<0.05$, compared with the NC group.

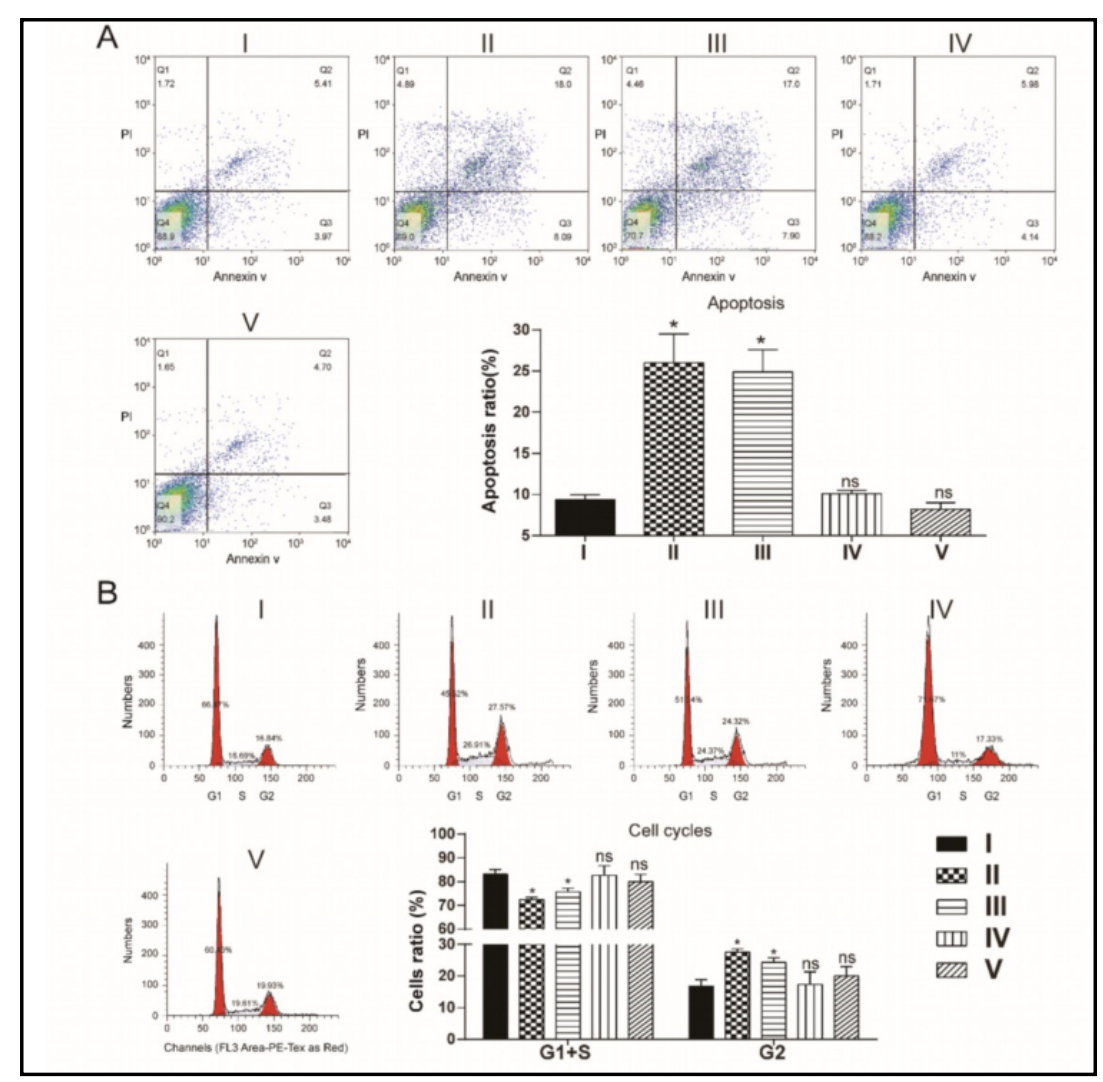




\section{Cellular Physiology Cell Physiol Biochem 2018;49:432-446 \begin{tabular}{ll|l} 
DOI: 10.1159/000492978 & $\begin{array}{l}\text { O } 2018 \text { The Author(s). Published by S. Karger AG, Basel } \\
\text { www.karger.com/cpb }\end{array}$ \\
\hline
\end{tabular}

Fig. 10. KCNQ10T1 knockdown inhibited MCF7 tumor growth in vivo. (A) KCNQ10T1 knockdown reduced the death rate of xenograft mice caused by tumor growth. (B) The tumor size in the KCNQ10T1 knockdown group was smaller than in the NC group. (C) The solid tumors, weighing 4 weeks after injection, indicated that KCNQ10T1 knockdown inhibited tumor growth. (D) KCNQ10T1 expression in tumor cells was measured and was reduced in shRNA groups. (E) miR-145 expression was higher in KCNQ10T1 knockdown groups. (F) CCNE2 expression was higher in KCNQ10T1 knockdown groups. * $\mathrm{P}$ $<0.05$, compared with the NC group.

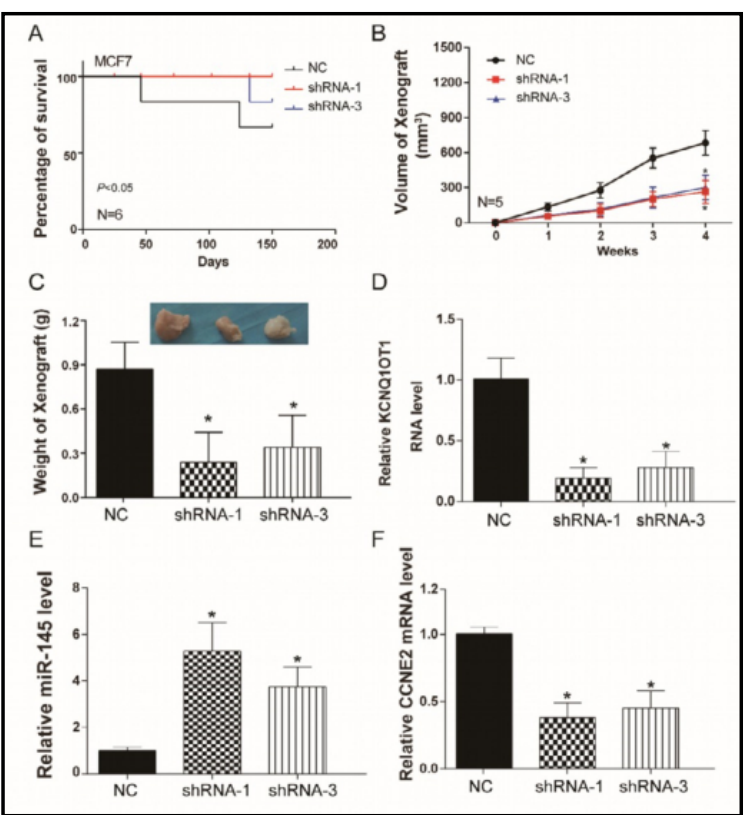

145 in BRCA were downloaded from starBase v2.0, and miR-145 was verified to be significantly downregulated in BRCA tissues (Fig. 4E), which was confirmed in our 18 paired samples (Fig. 4F). In addition, we confirmed that miR-145 was expressed at low levels in the four BRCA cell lines (Fig. $4 G)$.

To determine the target gene of miR-145 in human breast tissues, we first screened all the differentially expressed genes from the TCGA dataset (Fig. 5A). Then we captured three shared genes, FN1, CCNE2 and PPARG, through intersecting the predicted target genes dataset, differentially expressed genes dataset and gene set relating to KEGG pathways in cancer (Fig. 5B). Among these genes, PPARG was downregulated and FN1 and CCNE2 were both upregulated in BRCA

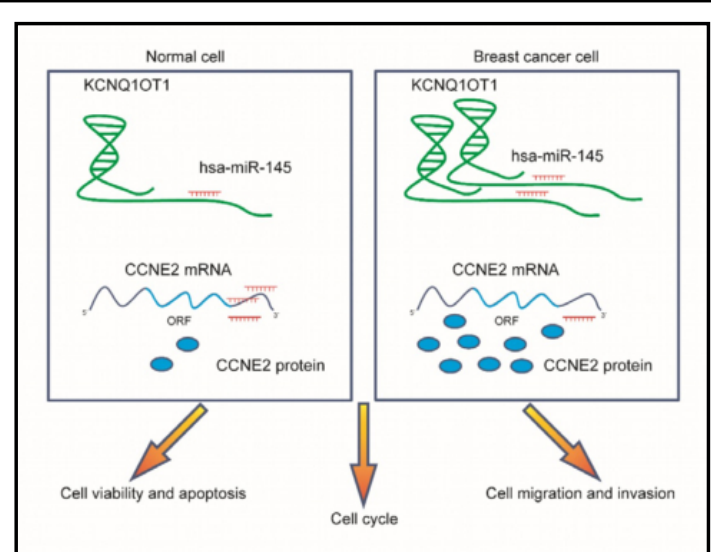

Fig. 11. Schematic diagram describes the action mechanism of KCNQ10T1 in breast cancer. MiR-145 targets the CCNE2 3'UTR, blocking the translation of the CCNE2 proteins, because of the reduced binding of KCNQ10T1 and miR-145 in normal breast cells compared with that in breast cancer cells.

tissues (Fig. 5C). Furthermore, StarBase v2.0 prediction results suggested that CCNE2 was highly expressed in BRCA (Fig. 5D), which was further verified in BRCA cell lines (Fig. 5E).

\section{The target relationship between KCNQ1OT1, miR-145 and CCNE2}

The Spearman rank correlation analysis results showed that miR-145 expression was negatively correlated with KCNQ10T1 and CCNE2 expression, while KCNQ10T1 expression was positively correlated with CCNE2 expression (Fig. 6A - 6C). Silencing KCNQ10T1 decreased the expression of CCNE2 and promoted the expression of miR-145 (Fig. 6D - 6F). Subsequently, the targeted relationships between miR-145 and KCNQ10T1 and miR-145 and CCNE2 were validated by dual luciferase reporter gene assays (Fig. 7A - 7B). The sequences of KCNQ10T1 (438 bp), containing the predicted miR-145-target site, and the whole length of the CCNE2 3'UTR (1833 bp) were amplified and recombined. MiR-145 only interfered with the reporter activity of wild-type (WT) constructs, which reflected the target relationships 
between miR-145 and IncRNA KCNQ10T1 and miR-145 and CCNE2. After transfection with miR-145 mimics, the expression level of miR-145 was considerably enhanced, while the miR145 inhibitor remarkably decreased the expression of miR-145 (Fig. 7C). To regulate the expression of CCNE2, siRNAs were used for CCNE2 knockdown, and vectors were generated for CCNE2 overexpression (Fig. 7D). The siRNAs of CCNE2 are designated siRNA-C1-C3 to distinguish them from the siRNA for KCNQ10T1. siRNA-C1 showed the most significant inhibitory effects on CCNE2 expression. The groups were divided into NC, siRNA-C1, miR145 mimics, siRNA-1 + miR-145-inhibitor and siRNA-1 + CCNE2 to evaluate the influence on mRNA and protein expression of CCNE2 (Fig. 7E - 7F). MiR-145 mimics decreased the expression of CCNE2, while the miR-145 inhibitor and CCNE2 reversed the KCNQ10T1 siRNA-1-mediated reduction in CCNE2. MiR-145 and siRNA-C1 inhibited cell proliferation and metastasis, while promoting cell apoptosis and cell cycle arrest at the G2 stage (Fig. 8 -Fig. 9). Significant changes were not observed in the siRNA-1 + miR-145 inhibitor and siRNA-1 + CCNE2 groups.

\section{KCNQ10T1 influenced tumor growth in vivo}

MCF7 cells transfected with sh-KCNQ10T1 were injected into nude mice, and tumor growth was observed. As shown in Fig. 10A, the survival rate of mice in the sh-KCNQ10T1 group was similar to that in the NC group. The tumors in the knockdown group (shRNA-1 and shRNA-3) had reduced volumes and masses relative to those in the NC group (Fig. 10B - 10C). After all mice were sacrificed in the fourth week, solid tumors were removed for further analysis. QRT-PCR results indicated that KCNQ10T1 and CCNE2 were considerably downregulated in the shRNA groups, while miR-145 was observably upregulated (Fig. 10D 10E). In normal cell homeostasis, decreased KCNQ10T1 sponges less miR-145, and residual miR-145 targets CCNE2 3'UTR to suppress the expression of CCNE2. In tumor cells, however, increased KCNQ10T1 reduces miR-145 and increases CCNE2, resulting in stronger cell proliferation and mobility, a weaker cell apoptosis ratio and a higher ratio of cells in G2 (Fig. 11).

\section{Discussion}

In this study, we demonstrated that KCNQ10T1 and CCNE2 were overexpressed in BRCA tissues and cells. In contrast, miR-145 was significantly reduced in BRCA tissues and cells. In addition, the target relationships between KCNQ10T1 and miR-145 and between miR145 and CCNE2 were verified. We found that knockdown of KCNQ10T1 inhibited viability and promoted apoptosis of MCF7 and SK-BR-3 cells. The in vivo experiment proved that knockdown of KCNQ10T1 induced tumors with the smallest volume and weight in nude mice. Together, the KCNQ10T1/miR-145/CCNE2 axis appears to play a crucial role in BRCA tumorigenesis and progression, providing a novel and promising therapeutic target.

LncRNAs are involved in many cellular processes, and their effects in cancers are demonstrated by their biological role in cell proliferation, apoptosis, and metastasis. Currently, numerous lncRNAs that serve as endogenous miRNA sponges have been shown to be involved in the initiation and development of BRCA [22]. The lncRNA NEAT1 was validated to promote cell invasion and proliferation in BRCA by negatively regulating miR218, which is a potential biomarker for prognosis and targeted therapy in BRCA patients [23]. The IncRNA BORG has been identified as a novel driver of genetic and epigenetic alterations which underlie the acquisition of metastatic and recurrent phenotypes in BRCA cells [14]. The overexpression of the lncRNA TUG1 significantly promotes cell migration and invasion, while TUG1 knockdown has the opposite effects [24]. Wang et al. indicated that an elevated expression of SOX2 can activate the IncRNA PVT1, promoting BRCA tumorigenesis and progression. Likewise, PVT1 may be a predictive biomarker for BRCA, and the interaction between PVT1 and SOX2 could be a therapeutic target in BRCA [15]. Consistent with previous 
studies, knockdown of the IncRNA KCNQ10T1 in the present study significantly increased miR-145 expression in BRCA and induced cell apoptosis and cell cycle arrest at the G2 phase.

MiRNAs, members of the noncoding RNA family, play important roles in posttranscriptional gene regulation. Numerous studies have demonstrated that miRNAs contribute to tumor formation and development, suggesting that they can play either an oncogenic or tumor suppressor role [25]. The underlying mechanisms of miR-145 in BRCA processes have increasingly been explored in previous studies. Liu et al. revealed that the reduced expression of miR-145 in BRCA was attributed to DNA methylation and demonstrated that miR-145 repressed cell migration and invasion by targeting ANGPT2 both in vivo and in vitro [26]. Zhao et al. identified that miR-145 suppressed BRCA cell migration by targeting FSCN-1 and blocked the epithelial-mesenchymal transition [27]. Zhang et al. verified that miR-145 acts as a tumor suppressor and that its downregulation in tumor tissues may contribute to the progression of BRCA through a mechanism involving ROCK1 [28]. Ding et al. suggested that miR-145 may inhibit TGF-beta1 protein expression, which may in turn induce the initiation and progression of BRCA [29]. In this research, miR-145 was found to be expressed at notably low levels in BRCA tissues and cells, and overexpression of miR-145 remarkably promoted cell apoptosis in BRCA by regulating CCNE2.

Previous studies have unraveled different regulatory mechanisms for the IncRNAmiRNA-mRNA axis in various carcinomas including BRCA. Zou et al. discovered the TP73AS1/miR-200a/ZEB1 regulatory loop in BRCA cells, which appears to promote cancer cell invasion and migration through regulation of E-cadherin and Twist expression [30]. The lncRNA H19 promoted proliferation and invasion of BRCA through the miR-152/DNMT1 axis, providing a novel insight into the occurrence and progression of BRCA [31]. Another study discovered that the IncRNA NEAT1 induced the epithelial-mesenchymal transition and 5-FU resistance through the miR-211/HMGA2 axis [32]. Similarly, our study established that knockdown of KCNQ10T1 suppressed CCNE2 expression by increasing the expression of miR-145, thereby inhibiting the propagation and metastasis of BRCA cells. The regulatory mechanisms of the KCNQ10T1/miR-145/CCNE2 network in BRCA was further elucidated in this research.

Although our findings have provided new insights into the downstream targets of KCNQ10T1, our knowledge is still insufficient to inform clinical practice. For example, KCNQ10T1 may influence the expression of CCNE2, and we corroborated that CCNE2 encodes a protein related to the cell cycle that may further influence cell viability and cell apoptosis, ultimately affecting migration and invasion [33]. Moreover, KCNQ10T1 interacts with other micromolecules, which might influence cell mobility [21]. Additional studies in larger homogeneous populations are therefore required to investigate the therapeutic and prognostic value of these biomarkers in the future.

In conclusion, our study substantiated that IncRNA KCNQ10T1 expression was significantly increased in BRCA and that KCNQ10T1 appeared to function as an oncogene by regulating the miR-145/CCNE2 axis. These findings provide a novel prognostic biomarker for the detection of patients at early stages and a potential therapeutic target for patients with BRCA.

\section{Acknowledgements}

This work was supported by Science and Technology Project of Zhejiang Provincial Administration of Traditional Chinese Medicine (No. 2017ZA030) and Science and Technology Project of Zhejiang Provincial Department of Health (No. 2011RCB010). 


\section{Cellular Physiology Cell Physiol Biochem 2018;49:432-446 \begin{tabular}{ll|l} 
and Biochemistry Published online: 29 August, 2018 & $\begin{array}{l}\text { (c) } 2018 \text { The Author(s). Published by S. Karger AG, Basel } \\
\text { www.karger.com/cpb }\end{array}$ \\
\hline
\end{tabular}}

Feng et al.: LncRNA KCNQ1OT1 Promotes Breast Cancer

\section{Disclosure Statement}

The authors confirm that they have no conflict of interests.

\section{References}

$>1$ Jemal A, Siegel R, Ward E, Hao Y, Xu J, Thun MJ: Cancer statistics, 2009. CA Cancer J Clin 2009;59:225-249.

-2 Sosa MS, Bragado P, Aguirre-Ghiso JA: Mechanisms of disseminated cancer cell dormancy: an awakening field. Nat Rev Cancer 2014;14:611-622.

3 Pantel K, Brakenhoff RH: Dissecting the metastatic cascade. Nat Rev Cancer 2004;4:448-456.

- Kolahdooz F, Jang SL, Corriveau A, Gotay C, Johnston N, Sharma S: Knowledge, attitudes, and behaviours towards cancer screening in indigenous populations: a systematic review. Lancet Oncol 2014;15:e504-516. Beca F, Polyak K: Intratumor Heterogeneity in Breast Cancer. Adv Exp Med Biol 2016;882:169-189. Fang Y, Wang J, Wu F, Song Y, Zhao S, Zhang Q: Long non-coding RNA HOXA-AS2 promotes proliferation and invasion of breast cancer by acting as a miR-520c-3p sponge. Oncotarget 2017;8:46090-46103.

7 Bagga S, Bracht J, Hunter S, Massirer K, Holtz J, Eachus R, Pasquinelli AE: Regulation by let-7 and lin-4 miRNAs results in target mRNA degradation. Cell 2005;122:553-563.

8 Shi Y, Ye P, Long X: Differential Expression Profiles of the Transcriptome in Breast Cancer Cell Lines Revealed by Next Generation Sequencing. Cell Physiol Biochem 2017;44:804-816.

-9 Lu X, Ma J, Chu J, Shao Q, Zhang Y, Lu G, Li J, Huang X, Li W, Li Y, Ling Y, Zhao T: MiR-129-5p Sensitizes the Response of Her-2 Positive Breast Cancer to Trastuzumab by Reducing Rps6. Cell Physiol Biochem 2017;44:2346-2356.

10 Lv ZD, Yang DX, Liu XP, Jin LY, Wang XG, Yang ZC, Liu D, Zhao JJ, Kong B, Li FN, Wang HB: MiR-212-5p Suppresses the Epithelial-Mesenchymal Transition in Triple-Negative Breast Cancer by Targeting Prrx2. Cell Physiol Biochem 2017;44:1785-1795.

-11 Wang J, Zeng H, Li H, Chen T, Wang L, Zhang K, Chen J, Wang R, Li Q, Wang S: MicroRNA-101 Inhibits Growth, Proliferation and Migration and Induces Apoptosis of Breast Cancer Cells by Targeting Sex-Determining Region Y-Box 2. Cell Physiol Biochem 2017;43:717-732.

12 Li XJ, Ren ZJ, Tang JH, Yu Q: Exosomal MicroRNA MiR-1246 Promotes Cell Proliferation, Invasion and Drug Resistance by Targeting CCNG2 in Breast Cancer. Cell Physiol Biochem 2017;44:1741-1748.

13 Yang C, Tabatabaei SN, Ruan X, Hardy P: The Dual Regulatory Role of MiR-181a in Breast Cancer. Cell Physiol Biochem 2017;44:843-856.

14 Gooding AJ, Zhang B, Jahanbani FK, Gilmore HL, Chang JC, Valadkhan S, Schiemann WP: The lncRNA BORG Drives Breast Cancer Metastasis and Disease Recurrence. Sci Rep 2017;7:12698.

15 Wang Y, Zhou J, Wang Z, Wang P, Li S: Upregulation of SOX2 activated LncRNA PVT1 expression promotes breast cancer cell growth and invasion. Biochem Biophys Res Commun 2017;493:429-436.

16 Zuo Y, Li Y, Zhou Z, Ma M, Fu K: Long non-coding RNA MALAT1 promotes proliferation and invasion via targeting miR-129-5p in triple-negative breast cancer. Biomed Pharmacother 2017;95:922-928.

17 Wang J, Wang X, Chen T, Jiang L, Yang Q: Huaier Extract Inhibits Breast Cancer Progression Through a LncRNA-H19/MiR-675-5p Pathway. Cell Physiol Biochem 2017;44:581-593.

$\checkmark 18$ Chiesa N, De Crescenzo A, Mishra K, Perone L, Carella M, Palumbo O, Mussa A, Sparago A, Cerrato F, Russo S, Lapi E, Cubellis MV, Kanduri C, Cirillo Silengo M, Riccio A, Ferrero GB: The KCNQ10T1 imprinting control region and non-coding RNA: new properties derived from the study of Beckwith-Wiedemann syndrome and Silver-Russell syndrome cases. Hum Mol Genet 2012;21:10-25.

19 Ren K, Xu R, Huang J, Zhao J, Shi W: Knockdown of long non-coding RNA KCNQ10T1 depressed chemoresistance to paclitaxel in lung adenocarcinoma. Cancer Chemother Pharmacol 2017;80:243-250.

20 Sunamura N, Ohira T, Kataoka M, Inaoka D, Tanabe H, Nakayama Y, Oshimura M, Kugoh H: Regulation of functional KCNQ10T1 lncRNA by beta-catenin. Sci Rep 2016;6:20690.

21 Gong W, Zheng J, Liu X, Liu Y, Guo J, Gao Y, Tao W, Chen J, Li Z, Ma J, Xue Y: Knockdown of Long Non-Coding RNA KCNQ10T1 Restrained Glioma Cells' Malignancy by Activating miR-370/CCNE2 Axis. Front Cell Neurosci 2017;11:84. 


\section{Cellular Physiology Cell Physiol Biochem 2018;49:432-446 \begin{tabular}{l|l|l} 
DOI: 10.1159/000492978 & $\begin{array}{l}\text { O } 2018 \text { The Author(s). Published by S. Karger AG, Basel } \\
\text { www.karger.com/cpb }\end{array}$
\end{tabular}}

Feng et al.: LncRNA KCNQ1OT1 Promotes Breast Cancer

22 Liu G, Hu X, Zhou G: Long non-coding RNA OR3A4 promotes proliferation and migration in breast cancer. Biomed Pharmacother 2017;96:426-433.

23 Zhao D, Zhang Y, Wang N, Yu N: NEAT1 negatively regulates miR-218 expression and promotes breast cancer progression. Cancer Biomark 2017;20:247-254.

-24 Fan S, Yang Z, Ke Z, Huang K, Liu N, Fang X, Wang K: Downregulation of the long non-coding RNA TUG1 is associated with cell proliferation, migration, and invasion in breast cancer. Biomed Pharmacother 2017;95:1636-1643.

25 Shayestehpour M, Moghim S, Salimi V, Jalilvand S, Yavarian J, Romani B, Mokhtari-Azad T: Targeting human breast cancer cells by an oncolytic adenovirus using microRNA-targeting strategy. Virus Res 2017;240:207214.

-26 Liu SY, Li XY, Chen WQ Hu H, Luo B, Shi YX, Wu TW, Li Y, Kong QZ, Lu HD, Lu ZX: Demethylation of the MIR145 promoter suppresses migration and invasion in breast cancer. Oncotarget 2017;8:61731-61741.

27 Zhao H, Kang X, Xia X, Wo L, Gu X, Hu Y, Xie X, Chang H, Lou L, Shen X: miR-145 suppresses breast cancer cell migration by targeting FSCN-1 and inhibiting epithelial-mesenchymal transition. Am J Transl Res 2016;8:3106-3114.

28 Zheng M, Sun X, Li Y, Zuo W: MicroRNA-145 inhibits growth and migration of breast cancer cells through targeting oncoprotein ROCK1. Tumour Biol 2016;37:8189-8196.

29 Ding Y, Zhang C, Zhang J, Zhang N, Li T, Fang J, Zhang Y, Zuo F, Tao Z, Tang S, Zhu W, Chen H, Sun X: miR145 inhibits proliferation and migration of breast cancer cells by directly or indirectly regulating TGF-beta1 expression. Int J Oncol 2017;50:1701-1710.

-30 Zou Q Zhou E, Xu F, Zhang D, Yi W, Yao J: A TP73-AS1/miR-200a/ZEB1 regulating loop promotes breast cancer cell invasion and migration. J Cell Biochem 2018;119:2189-2199.

-31 Li Z, Li Y, Li Y, Ren K, Li X, Han X, Wang J: Long non-coding RNA H19 promotes the proliferation and invasion of breast cancer through upregulating DNMT1 expression by sponging miR-152. J Biochem Mol Toxicol $2017 ; 31$.

-32 Li X, Wang S, Li Z, Long X, Guo Z, Zhang G, Zu J, Chen Y, Wen L: The lncRNA NEAT1 facilitates cell growth and invasion via the miR-211/HMGA2 axis in breast cancer. Int J Biol Macromol 2017;105:346-353.

33 Matsushita R, Seki N, Chiyomaru T, Inoguchi S, Ishihara T, Goto Y, Nishikawa R, Mataki H, Tatarano S, Itesako T, Nakagawa M, Enokida H: Tumour-suppressive microRNA-144-5p directly targets CCNE1/2 as potential prognostic markers in bladder cancer. Br J Cancer 2015;113:282-289. 